myocardial infarction: firstly, the diet in the acute phase (when the serious metabolic disturbances in the myocardium might well be influenced favourably or otherwise); and, secondly, the long-term restriction of animal fat in the hope of secondary prevention of coronary artery disease. Although clinically the role of increased circulating concentrations of free fatty acids present in the first 24 hours after myocardial infarction ${ }^{3}$ remains controversial, experimentally they are associated with cardiac arrhythmias, increased myocardial oxygen consumption, decreased contractility, and increased size of the infarct. ${ }^{4} \mathrm{~A}$ further rise in the plasma concentration of free fatty acids might be produced by a diet rich in cholesterol and fat, or by prolonged fasting. We know that the free fatty acid concentrations are reduced after patients with an infarction have had a normal meal $^{5}$ and this is a good reason to ensure that patients eat an adequate diet in the acute phase.

While intracellular imbalance of sodium and potassium is also an important feature of acute infarction, serious abnormalities of the plasma electrolyte concentrations are uncommon. The development of cardiac failure will lead to retention of sodium and fluid and a case could be made for the prophylactic restriction of added salt. Loss of potassium through the cell wall accompanies anoxic damage and may result in electrical instability. Attempts to prevent this effect by the intravenous infusion of a potassium, glucose, and insulin regimen gave disappointing results, ${ }^{6}$ and it is unlikely that giving potassium supplements by mouth could appreciably influence its concentration in the cells. On the other hand, hypokalaemia that develops owing to treatment with diuretics can be prevented by additional potassium.

What conclusions can we draw about diet for these patients? The main one seems to be that we are still ignorant about their dietary requirements. Possibly this is a matter of no importance, but until we know this for certain it would seem sensible to give our patients a diet rich in carbohydrate and low in fat and cholesterol with restriction of added salt. They should also avoid fasting and, if they are disinclined to eat, glucose drinks may be a helpful alternative. But this is another example of a common condition about which we know little and on which research would pay valuable dividends.

${ }^{1}$ Thorn, G W, et al, eds, Harrison's Principles of Internal Medicine, 8th ed, p 1275. New York, McGraw-Hill, 1977.

2 Warren, S E, Alpert, J S, and Francis, G S, American Heart fournal, $1978,95,130$.

${ }^{3}$ Kurien, V A, and Oliver, M F, Lancet, 1966, 2, 122.

4 Rowe, M J, Neilson, J M M, and Oliver, M F, Lancet, 1975, 1, 295.

5 Opie, L H, Bruyneel, K J J, and Kennelly, B M, British Heart fournal, 1975, 37, 700 .

${ }^{6}$ Medical Research Council Working Party on the Treatment of Myocardial Infarction, Lancet, 1968, 2, 1355.

\section{Arginine vasopressin in health and disease}

The posterior pituitary antidiuretic hormone, arginine vasopressin (AVP), normally controls the urine concentration by regulating the permeability of the collecting ducts to water. Nevertheless, a urine more concentrated than plasma can be formed without it. In the event of only a small amount of tubular fluid reaching the diluting site in the ascending limb of the loop of Henle (where more sodium is reabsorbed than water), the scope for dilution is limited, and the subsequent need for AVP is diminished. Thus the urine of patients with diabetes insipidus treated with diuretics and salt restriction becomes paradoxically more concentrated because glomerular filtration falls, proximal salt and water reabsorption increases, and less tubular fluid is delivered to the diluting site. ${ }^{1}$

Pituitary diabetes insipidus is rare; it may be caused by tumours in or near the pituitary, cerebral trauma, meningitis, or granulomatous deposits. Renal diabetes insipidus, the result of renal insensitivity to AVP, is rarer still; usually an inherited condition commoner in male members of affected families, ${ }^{2}$ it has occasionally developed as a result of acquired disease such as myeloma with hypercalcaemia and Bence Jones proteinuria ${ }^{3}$ and amyloidosis. ${ }^{4}$

Excessive secretion of AVP is more common than deficiency but it is much harder to define, except when it is due to ectopic production of AVP-like polypeptides by an oat-celled bronchial carcinoma (or rarely by another malignant tumour). The associated extracellular hyponatraemia is clinically important because water moves into body cells, which are now relatively hyperosmolar; the brain reacts to overhydration with symptoms of raised intracranial pressure-confusion, convulsions, and eventually coma. Ectopic secretion of AVP-like polypeptides can usually be diminished by radiotherapy or chemotherapy; parried by water restriction; or antagonised by lithium or demeclocycline, ${ }^{5}$ which inhibits AVP-sensitive medullary adenylcyclase in the collecting ducts. Acute symptoms of cerebral overhydration demand immediate treatment with hypertonic saline.

Hyponatraemia is, however, more commonly a complication of acute illness than of carcinoma, especially in the elderly. Usually it is associated with infections of lungs or central nervous system. In such patients the urine is frequently more concentrated than plasma, suggesting "inappropriate secretion of antidiuretic hormone." 6 Though the renal disturbances induced by illness and dehydration may themselves sometimes be sufficient to explain the paradox, the plasma AVP concentration is in fact usually either high or at least detectable in these hyponatraemic patients ${ }^{7}$ (whereas complete suppression would at first sight seem the appropriate response to their hyponatraemia). Judging the appropriateness of a plasma AVP concentration in a hyponatraemic patient is difficult, however, and the perplexed posterior pituitary responds as appropriately as it can to several conflicting claims. On the one hand, it releases AVP in response to dehydration as part of a co-ordinated response to preserve plasma volume; on the other hand, a fall in plasma osmolality inhibits AVP secretion. Preservation of plasma volume wins and AVP secretion is not completely suppressed-if at all. Normally treatment of the primary illness rapidly reverses this hyponatraemia without recourse to the measures which are necessary to combat ectopic secretion of AVP. ?

Pain and discomfort may play a larger part in stimulating AVP release in acute illness than has been realised. That AVP is released in response to surgery has long been recognised and attributed to trauma ${ }^{\times}$and anaesthesia, ${ }^{9}$ but pain by itself triggers release of AVP in $\operatorname{man}^{10}$ as in animals. Here, then, is another good reason for keeping patients as comfortable as possible-but preferably not with narcotic analgesics, which may themselves stimulate AVP release.

Inability to concentrate the urine to a normal maximum is common in real disease but is rarely of great symptomatic importance, other than contributing to nocturia. Impaired urinary concentrating ability is, however, a useful marker in clinical diagnosis. Prolonged water deprivation is the most potent stimulus to urine concentration, but it is also the least acceptable diagnostic test. For many years an intramuscular injection of vasopressin tannate in oil provided a more convenient clinical test, and this has now been replaced by intranasal synthetic deamino-D-arginine-vasopressin (desmopressin). ${ }^{1112}$ Intranasal desmopressin is also an excellent treatment for pituitary diabetes insipidus ${ }^{13}$ and has potential as treatment for nocturnal enuresis.

${ }^{1}$ Earley, L E, and Orloff, J, Fournal of Clinical Investigation, 1962, 41, 1988. ${ }_{2}^{2}$ Forssman, H, Acta Medica Scandinavica, 1945, 121, suppl 159, 1.

${ }^{3}$ Roussak, N J, and Oleesky, S, Quarterly fournal of Medicine, 1954, 23, 147. ${ }^{4}$ Carone, F A, and Epstein, F H, American Fournal of Medicine, 1960, 29, 539.

${ }^{5}$ Forrest, J N, et al, New England fournal of Medicine, 1978, 298, 173. 
${ }^{6}$ Bartter, F C, and Schwartz, W B, American fournal of Medicine, 1967, 42, 790.

7 Thomas, T H, et al, Lancet, 1978, 1, 621.

${ }^{8}$ Moran, W H, et al, Surgery, 1964, 56, 99.

${ }^{9}$ Dyball, R E J, Fournal of Physiology, 1975, 245, $119 \mathrm{P}$.

${ }^{10}$ Kendler, K S, Weitzman, R E, and Fisher, D A, Clinical Endocrinology, $1978,8,89$.

${ }_{11}$ Monson, J P, and Richards, P, British Medical fournal, 1978, 1, 24.

12 Delin, K, Aurell, M, and Ewald, J, British Medical fournal, 1978, 1, 757

13 British Medical fournal, 1977, 1, 1050.

\section{The nulliparous patient, the IUD, and subsequent fertility}

At the start of the rekindling of interest in intrauterine devices (IUDs) in the 1950s their use was generally confined to multiparous, older women, and nulliparous, younger women were usually advised to find an alternative means of contraception. Attempts were soon made, however, to design an IUD suitable for use by the young and childless woman. The accent was on finding a device which could be fitted without injuring the relatively tight cervical canal of the nulliparous woman. This problem has been reduced (but not entirely overcome) with the development of narrow-gauge IUD inserters, and the fitting of IUDs in nulliparous women has now become commonplace.

Nevertheless, the use of IUDs in this population has never been totally accepted, and recent publications have once again questioned its advisability. The causes for concern are not the problems associated with the fitting of the IUD-although these are not denied-but the longer-term consequences. These include a possible raised incidence of pregnancy, of expulsion of the device, and of bleeding or pain among nulliparous women when compared with parous women ${ }^{1}$; a raised incidence of pelvic inflammatory disease ${ }^{2}$; and the difficulties of administering an efficient IUD service among these women. ${ }^{3}$

After reviewing data collected from 20000 IUD users in Britain Snowden et al $^{3}$ suggested that the IUD should not be the first choice for nulliparous patients, in whom the doctor should seriously consider alternative methods of contraception. They argued that (in addition to the points raised above) if a nulliparous woman abandons the use of an IUD owing to unacceptable side effects her experience may discourage her from trying it again when her family is complete-the time at which the IUD may be the most suitable contraceptive for many women.

The most serious doubt about the use of the IUD is that it may impair ability to conceive or complete a subsequent pregnancy. The evidence we have suggests that in most cases the ability to conceive after wearing an IUD is not unduly retarded ${ }^{4}$ but the same cannot be said for women who have had pelvic infection, spontaneous abortion, or ectopic pregnancy.

The link between the use of the IUD and pelvic inflammatory disease is undoubted, ${ }^{6-8}$ but the problems of diagnosis and reporting have repeatedly thwarted attempts to establish the incidence with any accuracy. Despite these difficulties, Westrom et $a l^{2}$ have shown that women wearing an IUD had a threefold increase in the rate of salpingitis when compared with other women and that, when controlled for parity, the increase among nulliparous IUD users was seven times that of nulliparous non-IUD users.

What makes these findings the more worrying is the apparent relation between pelvic infection and subsequent infertility. ${ }^{9}$ Furthermore, when pregnancy does occur the proportion who miscarry or who have an ectopic pregnancy is higher among IUD users than among non-IUD users. ${ }^{10-12}$ The effect of pelvic infection, spontaneous abortion, and ectopic pregnancy on the outcome of subsequent (possibly wanted) pregnancies is a matter of especial concern to those who are using an IUD as a means of delaying their first pregnancy.
At present we cannot categorically state that nulliparous women should discontinue the use of the IUD, but sufficient doubt has been raised to suggest the need for a prospective study designed to examine its effects in some detail-a call we made in $1976 .{ }^{13}$ Now, as then, we need a controlled prospective study among adequate numbers of nulliparous womenpreferably including a substantial proportion (of toth past users and non-users of IUDs) with a previous diagnosis of pelvic infection. If the main cause of illness among IUD users is associated with infection and if pelvic infection affects subsequent fertility, then such a study among nulliparous women is overdue.

${ }^{1}$ Weiner, E, Berg, A A, and Johansson, I, British fournal of Obstetrics and Gynaecology, 1978, 85, 204.

2 Westrom, L, Bengtsson, L P, and Mardh, P, Lancet, 1976, 2, 221.

${ }^{3}$ Snowden, R, Williams, $\mathrm{M}$, and Hawkins, D, The IUD-A Practical Guide. London, Croom Helm, 1977.

4 Tietze, C, and Lewit, S, Studies in Family Planning, 1970, No 55, 1.

Vessey, M P, et al, British Medical fournal, 1978, 1, 265.

6 Targum, S D, and Wright, N H, American fournal of Epidemiology, 1974, 100, 262.

' Faulkner, W L, and Ory, H W, fournal of the American Medical Association, 1976, 235, 1851.

${ }^{8}$ Vessey, M P, et al, fournal of Biosocial Science, 1976, 8, 373.

9 Westrom, L, American fournal of Obstetrics and Gynecology, 1975, 121, 707.

10 Tatum, H J, and Schmidt, F H, Fertility and Sterility, 1977, 28, 407.

${ }^{11}$ Snowden, R, Family Planning Association Medical Newsletter, 1976, 59, 1.

12 Beral, V, British Fournal of Obstetrics and Gynaecology, 1975, 82, 775.

${ }^{13}$ British Medical fournal, 1976, 2, 77.

\section{Children's Joint Committee}

The report ${ }^{1}$ of the Committee on Child Health Services (the Court Report) was published in December 1976. It was widely discussed throughout 1977, but unfortunately most of the argument was concerned with the functions and status of various professional groups rather than with the need to improve services provided for children. The Government's recommendations, which followed these discussions, were published in January 1978 and proved disappointing; for while the DHSS claimed to accept the overall philosophy of the Court Report it agreed to few of the specific measures that had been recommended. Perhaps the blame, if blame there is, should be widely shared. The Court Report was the outcome of a painstaking study of the history and current position of the child health services and provided an imaginative and far-reaching strategy to improve them-but it emphasised that the reorganisation it proposed might take 15-20 years.

Possibly the Court Report would not have aroused such a strong negative reaction among professional groups if its conclusions had concentrated more on principles and less on changes in status (general practitioner paediatricians, consultant community paediatricians, and child health visitors). The negative reactions were compounded by the chronic lack of finance and may explain the Government's meagre responsebut the fact remains that our child health services cannot match the exciting improvements in many other European countries.

One recommendation now implemented is the formation of a children's joint committee. The Court Report stated, "It is our belief that children have special needs which they cannot articulate for themselves and that society has therefore a duty to ensure that these are identified and cogently represented." It therefore recommended that a committee should be set up to give advice directly to the Secretary of State for Health and Social Services. To be effective such a committee needs to be small, with membership based on ability rather than representing sectional interests. These requirements are fulfilled by the composition of the new Children's Joint Committee (the names of the members

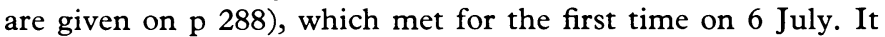

